\title{
EFISIENSI PENGGUNAAN FAKTOR-FAKTOR PRODUKSI PADA TEKNOLOGI PENDEDERAN IKAN LELE (Clarias $s p$ ) SANGKURIANG
}

\section{EFFICIENCY OF PRODUCTION FACTORS APPLICATION ON CATFISH (Clarias $s p$ ) Var. SANGKURIANG HATCHERY TECHNOLOGY}

\author{
Ristina Siti Sundari ${ }^{1}$, Yudhi Arie Priyanto ${ }^{2}$ \\ ${ }^{1}$ Agribisnis Universitas Perjuangan Tasikmalaya \\ ${ }^{2}$ Program Studi Ilmu dan Teknologi Benih, Sekolah Pascasarjana, Institut Pertanian Bogor \\ Korespondensi: ristina.sitisundari@yahoo.com, yudhi_ap@apps.ipb.ac.id
}

\begin{abstract}
Catfish is now the rising favorite fish to consumpt. This research was conducted to know the influence of application of production factors either simultaneously or partially and also their efficiency hatchery maintenance of Catfish varr Sangkuriang (Clarias sp). The dependent variable was product of benih $(\mathrm{Y})$ and the independent variable were the area of pool $\left(\mathrm{X}_{1}\right)$, benih $\left(\mathrm{X}_{2}\right)$, feed $\left(\mathrm{X}_{3}\right)$ and labour $\left(\mathrm{X}_{4}\right)$. The other variables descriptively tested were the price of baby catfish (Py) and production factors (Px). The method of research used case study and data gathered purposively from the group of hatchery maintence of catfish varr. Sangkuriang at Sukaratu Village, Sukaratu - Tasikmalaya. The Data were analyzed by using Cobb Douglas production function whereas MPV and Px ratio was counted to find out the level of efficiency within each production factors. The result showed that the analysis of production factors was significant simultaneously. Whereas the analysis of each production factor indicated that either area or labour production factors were non significant partially. But the production factors of benih and feed partially were significant toward production of baby catfish on the hatchery maintenance catfish varr Sangkuriang. The value of Production Elasticity was less than one. It showed that hatchery is in decreasing return to scale. The result of analysis of production factors's efficiency indicated that area and benih have not already been efficient. So, they were necessary to increase the amount of those production factors. Whereas, production factors of feed and labour were not efficient. So, reducing the amount of application of production factors was necessary to reduce the amount.
\end{abstract}

Keyword: catfish, efficiency, hatchery maintenance, production factors

\begin{abstract}
ABSTRAK
Penelitian ini dilaksanakan dengan tujuan untuk mengetahui pengaruh penggunaan faktor-faktor produksi baik secara simultan maupun secara parsial dan efisiensi penggunaan faktor-fakktor produksi pada teknologi pendederan ikan lele Sangkuriang. Variabel terikat $(\mathrm{Y})$ adalah Hasil produksi benih ikan lele Sangkuriang dan variabel bebas adalah kolam $\left(\mathrm{X}_{1}\right)$, benih $\left(\mathrm{X}_{2}\right)$, pakan $\left(\mathrm{X}_{3}\right)$ dan tenaga kerja $\left(\mathrm{X}_{4}\right)$. Variabel lain tidak dilakukan pengujian tetapi dianalisis secara deskriptif yaitu terhadap harga produksi (Py) dan harga faktor produksi. Penelitian menggunakan metode studi kasus dan responden ditentukan secara sengaja dari kelompok usaha teknik pendederan ikan lele Sangkuriang di Desa Sukaratu Kecamatan Sukaratu Kabupaten Tasikmalaya. Waktu Penelitian mulai bulan Juni - October 2013. Data dianalisis menggunakan fungsi produksi Cobb Douglas dan rasio NPM dengan Px dihitung untuk memperoleh tingkat efisiensi masing-masing faktor produksi. Hasil penelitian menunjukkan bahwa analisis faktor-faktor produksi secara simultan berpengaruh nyata terhadap hasil produksi pendederan ikan lele Sangkuriang. Sedangkan pada analisis secara parsial faktor produksi kolam dan tenaga kerja tidak berpengaruh tetapi faktor produksi benih dan pakan berpengaruh nyata terhadap produksi pendederan ikan lele Sangkuriang. Elastisitas produksi kurang dari satu, termasuk dalam skala usaha yang menurun (Decreasing Return to Skill). Hasil analisis efisiensi faktor-faktor produksi menunjukkan bahwa faktor produksi kolam dan benih belum efisien. Maka perlu menambah faktor produksi tersebut. Sedangkan faktor produksi pakan dan tenaga kerja tidak efisien. Maka perlu menurunkan jumlah faktor produksi tersebut.
\end{abstract}

Kata kunci: efisiensi, faktor-faktor produksi, ikan lele, pendederan 


\section{PENDAHULUAN}

\section{Latar belakang}

Dikenal sebagai negara agraris dan negara maritim yang potensial untuk bidang perikanan karena Indonesia memiliki sumber daya perikanan yang cukup besar. Diperkirakan sekitar 16 persen spesies ikan yang ada di dunia hidup di perairan Indonesia. Menurut data, total jumlah jenis ikan yang terdapat di perairan Indonesia mencapai 7.000 jenis. Hampir sekitar 2.000 spesies diantaranya merupakan jenis ikan air tawar (Khairuman et al. 2008). Di sisi lain Indonesia memiliki perairan daratan yang sangat luas yang dapat dimanfaatkan sebagai media agribisnis perikanan darat yang memiliki nilai ekonomi tinggi. Menurut Kartamihardja et. al. (2007) dalam Khairuman \& Amri (2008) luas perairan daratan Indonesia mencapai 54 juta ha dan yang termasuk perairan budidaya seluas 0.65 juta ha mencakup kolam, sawah dan tambak.

Kegiatan revitalisasi ikan lele diharapkan dapat memberikan kontribusi yang signifikan terhadap pertumbuhan ekonomi, perolehan devisa, penciptaan lapangan kerja, peningkatan pendapatan dan kesejahteraan masyarakat dengan konsep minapolitan, yaitu pengembangan perikanan di wilayah perkotaan.

Dalam usaha budidaya ikan lele ada beberapa kegiatan besar yang harus ditingkatkan secara bersamaan yaitu usaha pembenihan, pendederan dan pembesaran. Kegiatan ini tidak dapat dipisahkan dalam prosesnya.

Menurut Mahyudin (2008), untuk menunjang keberhasilan budidaya ikan, salah satu faktor yang menentukan adalah tersedianya benih deder yang memenuhi syarat baik kualitas, kuantitas, maupun kontinuitasnya.

Ikan lele dapat dibudidayakan di lahan sempit seperti terpal juga tahan dalam padat tebar yang tinggi. Di samping itu lebih tahan terhadap penyakit, kualitas air yang menurun serta pertumbuhan yang cepat jika pakan tersedia maksimal terutama pada fase benih mulai hari ke 3 (tiga) setelah menetas., kemudian dilakukan pendederan. Pendederan adalah kegiatan pemeliharaan benih sampai dihasilkan benih yang siap ditebarkan di kolam pembesaran. Padat tebar yang dianjurkan pada segmen pendederan adalah 300 - 600 ekor $/ \mathrm{m} 2$ (Mahyudin 2008).
Dari kegiatan teknik pendederan yang terdapat di Tasikmalaya masih terlihat ada beberapa faktor produksi seperti tenaga kerja yang memberi pakan cenderung lebih sering. Sehingga dipertanyakan apakan hal demikian sudah efisien secara teknis maupun sekonomis. Dari hasil observasi lapangan dapat dilihat bahwa penggunaan faktor-faktor produksi untuk teknik pendederan ikan Lele Sangkuriang yang ada di Kabupaten Tasikmalaya belum diketahui efisiensinya. Dengan demikian, ingin diketahui bagaimana pengaruh penggunaan faktor-faktor produksi terhadap hasil produksi dalam usaha teknik pendederan ikan Lele Sangkuriang di Desa Sukaratu Kecamatan Sukaratu dan bagaimana efisiensi penggunaan faktor-faktor produksi dalam usaha teknik pendederan ikan Lele Sangkuriang di Desa Sukaratu Kecamatan Sukaratu.

\section{METODE PENELITIAN}

Berkaitan dengan fokus penelitian, penelitian ini menggunakan metode studi kasus pada Kelompok Budidaya Ikan Lele Sangkuriang di Desa Sukaratu Kecamatan Sukaratu Kabupaten Tasikmalaya. Data yang dikumpulkan adalah data primer yang diperoleh langsung dari petani pembudidaya ikan Lele Sangkuriang dengan menggunakan daftar pertanyaan (quesioner) dan data sekunder yang diperoleh dari instansi-instansi terkait dan literatur yang berhubungan dengan penelitian ini

Responden ditentukan secara sengaja (purposive) di Kelompok Budidaya Ikan Lele Sangkuriang Desa Sukaratu Kecamatan Sukaratu Kabupaten Tasikmalaya sebanyak 25 responden.Variabel-variabel yang digunakan adalah: Produksi (Y), Luas Kolam $\left(X_{1}\right)$, Benih $\left(X_{2}\right)$, Pakan $\left(X_{3}\right)$, Tenaga Kerja $\left(\mathrm{X}_{4}\right)$, Harga Hasil Produksi (Py) dan Harga Faktor Produksi (Px).

Hubungan fungsional antara input dengan output (faktor-faktor produksi dengan hasil produksi) menggunakan fungsi Cobb-Douglas. Secara spesifik, hubungan fungsional antara faktor-faktor produksi dengan hasil produksi tersebut dinyatakan dalam bentuk persamaan fungsi CobbDouglas:

$$
Y=\beta_{0} X 1^{\beta 1} X 2^{\beta 2} X 3^{\beta 3} X 4^{\beta 4} e^{\mu}
$$

Ditransformasi ke dalam bentuk fungsi linier logaritma, maka model fungsi produksi dapat diformulasikan dalam persamaan : 
$\operatorname{Ln} Y=\ln \beta_{O}+\beta_{1} \ln X_{1}+\beta_{2} \ln X_{2}+\beta_{3} \ln X_{3}+$ $\beta_{4} \ln X_{4}+\mu \ln e$

Keterangan :

$\mathrm{Y} \quad=$ Hasil produksi (output)

Bo = konstanta (koefisien intercept)

$\beta 1 \ldots \beta 4=$ koefisien regresi untuk tiap faktor produksi (input)

$\mathrm{X} 1=$ luas kolam

$\mathrm{X} 2=$ benih

$\mathrm{X} 3=$ pakan

$\mathrm{X} 4=$ tenaga kerja

e $\quad=$ pengaruh faktor lain atau eror

Uji F

Uji $\mathrm{F}$ dilakukan untuk mengetahui apakah faktor-faktor produksi yang digunakan secara simultan berpengaruh nyata atau tidak terhadap hasil produksi pada usaha teknik pendederan Lele Sangkuriang.

\section{Koefisien determinasi (R2)}

Nilai koefisien determinasi digunakan untuk mengetahui besarnya pengaruh faktor produksi (X) terhadap hasil (Y) dengan menggunakan persamaan:

$$
\mathrm{R} 2=\frac{\Sigma \beta \mathrm{i} \cdot \Sigma \mathrm{xiy}}{\Sigma \mathrm{yi2} \text { atau } \mathrm{R} 2}=\frac{\text { JKRegresi }}{\text { JKTotal }}
$$

Keterangan:

$\beta \mathrm{i}=$ taksiran koefisien regresi variable ke $i$

xi $=$ variabel bebas ke i dan

$\mathrm{y} \quad=$ variabel terikat

JK = jumlah kuadrat

\section{Uji t}

Pengaruh masing-masing faktor produksi secara parsial dilakukan uji t.

Keterangan :

$$
\mathrm{t} \text { statistik } \rightarrow \mathrm{t}=\frac{\beta \mathrm{i}}{\mathrm{s}(\beta \mathrm{i})}
$$

$\mathrm{Bi}=$ taksiran koefisien regresi variabel ke $\mathrm{i}$ $\mathrm{S}(\beta \mathrm{i})=$ simpangan baku variabel $\mathrm{ke} \mathrm{i}$

Berdasarkan fungsi Cobb-Douglas, nilai $\beta I$ yang diperoleh merupakan elastisitas produksi dari tiap-tiap faktor produksi.

$$
\begin{aligned}
\text { Eprod } & =\beta \mathrm{i}=\frac{\mathrm{dY}}{\mathrm{dXi}} \cdot \frac{\mathrm{Xi}}{\mathrm{Yi}} \\
\beta \mathrm{i} & =(\mathrm{PM}) \cdot \frac{1}{\mathrm{PR}} \\
\beta i & =\frac{\mathrm{PM}}{\mathrm{PR}} \rightarrow P M=\beta i . P R
\end{aligned}
$$

Elastisitas produksi dari masingmasing faktor produksi dalam fungsi CobbDouglas dinyatakan dalam tiga alternative yang menunjukkan skala usaha: $\sum \beta \mathrm{i}>$ 1, (Increasing Return to Scale). $\sum \beta \mathrm{i}<1$, (Decreasing Return to Scale) dan $\sum \beta \mathrm{i}=1$, (Constant Return to Scale). Produk Marginal dari suatu faktor produksi diperoleh dari hasil perkalian koefisien regresi faktor produksi yang bersangkutan dengan rasio rata-rata produksi tersebut. yaitu :

$$
P M X i=\frac{d Y}{d X i}=\beta i \cdot \frac{Y}{X i}
$$

Keterangan:

$$
\mathrm{PM}=\frac{\mathrm{dY}}{\mathrm{dXi}}=\text { Produk Marginal }
$$

$\mathrm{PR}=\frac{\mathrm{Y}}{\mathrm{Xi}}=$ Produk Rata-rata

Efisiensi ekonomis (keuntungan maksimum) diperoleh dari persamaan:

$$
\begin{aligned}
\frac{\mathrm{dProfit}}{\mathrm{dXi}} & =\left(\mathrm{PY} \cdot \frac{\mathrm{dY}}{\mathrm{dXi}}-\mathrm{PX}\right)=0 \\
& =\mathrm{PY} \cdot \mathrm{PM}-\mathrm{PX}=0 \\
& =\mathrm{PY} \cdot \mathrm{PM}=\mathrm{PX} \\
& =\mathrm{NPM}=\mathrm{PX}
\end{aligned}
$$

Tingkat efisiensi penggunaan faktorfaktor produksi dihitung menggunakan rasio Nilai Produk Marginal ke i dengan harga faktor produksi ke i (PXi) yaitu jika :

1. $\frac{\text { NPMxi }}{\text { Pxi }}<1$, tidak efisien, perlu dikurangi pemakaian faktor produksi.

2. $\frac{\text { NPMxi }}{\text { Pxi }}>1$, belum efisien, perlu ditingkatkan pemakaian faktor produksi.

3. $\frac{\text { NPMxi }}{\text { Pxi }}=1$, penggunaan faktor produksi ke i sudah efisien.

Efisiensi ekonomis (keuntungan maksimum) dengan kombinasi faktor-faktor produksi yang efisien harus memenuhi syarat keharusan, yaitu:

$$
\frac{\text { NPMxi }}{\text { Pxi }}=1
$$

Keterangan:

NPMXi =Nilai Produk Marginal yang diperoleh dari hasil perkalian produk marginal faktor produksi terentu dengan harga satuan produk.

PXi = Harga input dari setiap faktor 
produksi yang digunakan.

\section{HASIL DAN PEMBAHASAN}

\section{Analisis fungsi produksi}

Hubungan fisik antara variabel yang dijelaskan $(\mathrm{Y})$ dengan variabel yang menjelaskan (X) digambarkan dengan fungsi produksi. Fungsi produksi yang digunakan pada penelitian ini untuk menggambarkan hubungan antara faktor produksi dengan hasil produksi pada usaha teknik pendederan ikan lele Sangkuriang untuk satu kali proses produksi adalah fungsi produksi Cobb Douglas.

Fungsi Cobb Douglas digunakan dalam penelitian ini karena terdapat lebih dari dua variabel bebas, maka fungsi yang memadai adalah fungsi produksi Cobb Douglass. Menurut pengalaman para peneliti untuk penelitian yang menyangkut komoditas pertanian dan perikanan dengan adanya kurva kenaikan hasil yang berkurang lebih cocok menggunakan fungsi Cobb Douglas karena lebih mudah ditransformasikan ke dalam bentuk linier dan nilai koefisien regresinya menunjukkan nilai besaran elastisitas produksi (Soekartawi 2002).

Hubungan fungsional antara faktorfaktor produksi dengan hasil produksi tersebut dinyatakan dalam persamaan fungsi Cobb Douglas:

$Y=\beta_{0} X_{1}^{\beta 1} X_{2}^{\beta 2} X_{3}^{\beta 3} X_{4}^{\beta 4} e \mu$

$Y=1,799 X_{1}^{0,269} X_{2}^{0,396} X_{3}^{0,104} X_{4}^{0,054}$

Untuk memudahkan pendugaan fungsi produksi Cobb Douglas, maka nilai yang didapat ditranformasikan ke dalam logaritma natural menjadi :

$$
\begin{aligned}
& \operatorname{Ln} Y=0,587+0,269 \operatorname{Ln} X_{1}+0,396 \operatorname{Ln} X_{2}+ \\
& 0,104 \operatorname{Ln} X_{3}-0,054 \operatorname{Ln} X_{4} \\
& \mathrm{Se} \quad=(0,846) ; \quad(0,129) ; \quad(0,182) ; \quad(0,044) ; \\
& (0,130) \\
& \mathrm{t}^{-}{ }_{\text {hit }}=(0,694) ;(2,078) ;\left(2,173^{*}\right) ;\left(2,354^{*}\right) \text {; } \\
& (-0,416) \\
& \mathrm{F}_{\text {hit }}=\left(14,897^{* *}\right) ; \mathrm{F}_{05}=2,87 ; \mathrm{F}_{01}=4,43 \text {; } \\
& \mathrm{ta} / 2=2,086 \\
& \mathrm{R}=0,865 ; \mathrm{R} 2=0,749 ; \text { Adjusted R2 = } \\
& 0,698 ; \text { See }=0,626
\end{aligned}
$$

Hasil analisis dengan menggunakan program SPSS 19 diperoleh nilai koefisien determinasi $\left(\mathrm{R}^{2}\right)$ sebesar 0.749. Hal ini dapat diinterpretasikan bahwa secara bersamasama keempat faktor produksi yaitu kolam $\left(\mathrm{X}_{1}\right)$, benih $\left(\mathrm{X}_{2}\right)$, pakan $\left(\mathrm{X}_{3}\right)$ dan tenaga kerja $\left(\mathrm{X}_{4}\right)$ mampu menjelaskan perubahan yang terjadi terhadap produksi benih ikan lele Sangkuriang (Y) sebesar 74.9 persen. Sisanya sebesar 25.1 persen produksi benih ikan lele Sangkuriang dijelaskan oleh faktor lain atau variabel lain di luar keempat faktor produksi yang tidak diteliti.

Uji F (ANOVA) menunjukkan hasil analisis $\mathrm{F}_{\text {hitung }}$ sebesar 14.897 lebih besar dari $\mathrm{F}_{\text {tabel }}$ sebesar 2.87 pada taraf kepercayaan 95 persen dan 4.43 pada taraf kepercayaan 99 persen. Hasil uji $\mathrm{F}$ ini memutuskan untuk menolak $\mathrm{H}_{0}: \beta_{1}=\beta_{2}=\beta_{3}=\beta_{4}=0$. Hal ini memberikan kesimpulan bahwa variabelvariabel yang dianalisis yaitu kolam $\left(\mathrm{X}_{1}\right)$, benih $\left(\mathrm{X}_{2}\right)$, pakan $\left(\mathrm{X}_{3}\right)$ dan tenaga kerja $\left(\mathrm{X}_{4}\right)$ secara simultan berpengaruh sangat nyata terhadap produksi benih ikan lele Sangkuriang (Y). Hal ini juga menunjukkan bahwa model fungsi produksi dapat digunakan untuk analisis selanjutnya.

Hasil Uji-t pada Tabel 1 menunjukkan bahwa penggunaan faktor produksi luas kolam $\left(\mathrm{X}_{1}\right)$ dan tenaga kerja $\left(\mathrm{X}_{4}\right)$ secara parsial tidak berpengaruh nyata terhadap produksi benih ikan lele Sangkuriang (Y). Hal ini dapat dilihat dari nilai $\mathrm{t}\left(\mathrm{X}_{1}\right)$ sebesar 2.07 dan 0.33 dengan level of significant 0.05 dan 0.69. Jumlah tenaga kerja tidak berpengaruh nyata terhadap hasil produksi benih. Sedangkan penggunaan faktor produksi benih $\left(\mathrm{X}_{2}\right)$ dan pakan $\left(\mathrm{X}_{3}\right)$ secara parsial berpengaruh nyata terhadap produksi benih ikan lele Sangkuriang (Y). Hal ini dapat dilihat dari nilai $\mathrm{t}\left(\mathrm{X}_{2}\right)$ sebesar 2.17 dan $\mathrm{t}\left(\mathrm{x}_{3}\right)$ sebesar 2.35 dengan level of significant 0.04 dan 0.02. Hal ini menunjukkan bahwa jumlah benih dan pakan secara nyata dapat mempengaruhi besarnya hasil produksi benih ikan Lele Sangkuriang.

Koefisien regresi menunjukkan elastisitas produksi. Dalam penelitian ini nilai elastisitas produksi $\left(\mathrm{Ep}_{\mathrm{i}}\right)$ variabel $\mathrm{Xi}$ secara keseluruhan adalah 0.72. Nilai $\mathrm{Ep}_{\mathrm{i}}$ tersebut kurang dari satu $\left(\mathrm{Ep}_{\mathrm{i}}<1\right)$, maka produk marjinal akan berkurang walaupun faktor produksi naik, yang mana pengurangan akan sesuai dengan nilai $\beta i$ (koefisien regresi). Kondisi ini termasuk dalam alternatif Decreasing Return to Scale. Hal ini menunjukkan bahwa proses produksi berada dalam skala usaha yang menurun, artinya jika faktor produksi bertambah satu satuan maka hasil produksi meningkat kurang dari satu satuan, dalam hal ini hanya meningkat sebesar 0.72 satuan. Perubahan faktor produksi dapat dilihat pada Gambar 1.

Nilai elastisitas produksi yang 
kurang dari satu $\left(\mathrm{Ep}_{\mathrm{i}}<1\right)$ berada di wilayah $z$ yaitu pada skala usaha yang menurun (Decreasing Return to Scale). Penambahan faktor produksi secara keseluruhan tidak menguntungkan lagi. Namun demikian, bisa dicermati secara spesifik faktor produksi apa saja yang benar-benar bisa menambah hasil dan yang mengurangi hasil jika dilakukan penambahan dan pengurangan, bisa dilihat dengan analisis efisiensi.

\section{Analisis efisiensi penggunaan faktor- faktor produksi}

Soekartawi (2002) menyatakan bahwa penggunaan faktor produksi secara ekonomis akan efisien apabila rasio antara NPM dengan Pxi sama dengan satu $\left(\frac{\mathrm{NPMxi}}{\mathrm{Pxi}}=\right.$ 1). Apabila rasio ini lebih besar dari satu ( $\frac{\mathrm{NPMxi}}{\mathrm{Pxi}}>$ 1) maka penggunaan faktor produksi belum efisien. Apabila rasio ini lebih kecil dari satu $\left(\frac{\mathrm{NPMxi}}{\mathrm{Pxi}}<1\right)$ maka penggunaan faktor produksi sudah tidak efisien dan harus dikurangi.

Berdasarkan Tabel 2, melalui transformasi logaritma natural rata-rata benih yang dihasilkan senilai 4.212 dengan harga benih senilai Rp.4.99. Rasio NPM dan Px untuk luas kolam $\left(\mathrm{X}_{1}\right)$ sebesar 1.46. Berarti $\frac{\text { NPMxi }}{\text { Pxi }}>1$ Hal ini menunjukkan bahwa faktor produksi luas kolam $\left(\mathrm{X}_{1}\right)$ belum efisien, diperlukan penambahan faktor produksi luas kolam senilai 2.58 untuk mencapai efisien. Rasio NPM dan Px untuk benih $\left(\mathrm{X}_{2}\right)$ sebesar 2.36 yang berarti lebih dari satu ( $\left.\frac{\text { NPMxi }}{\text { Pxi }}>1\right)$. Hal ini menunjukkan bahwa faktor produksi benih $\left(\mathrm{X}_{2}\right)$ juga belum efisien, untuk mencapai efisien perlu dilakukan penambahan faktor produksi benih senilai 6.16 agar efisien.

Rasio NPM dan Px untuk pakan $\left(\mathrm{X}_{3}\right)$ sebesar 0.18 dan untuk tenaga kerja $\left(\mathrm{X}_{4}\right)$ sebesar -0.17 yang berarti kurang dari satu. Hal ini menunjukkan bahwa faktor produksi pakan $\left(\mathrm{X}_{3}\right)$ dan tenaga kerja $\left(\mathrm{X}_{4}\right)$ tidak efisien sehingga perlu dikurangi penggunaannya. Pengurangan faktor produksi pakan $\left(\mathrm{X}_{3}\right)$ senilai 4.29 satuan dan faktor produksi tenaga kerja $\left(\mathrm{X}_{4}\right)$ senilai 4.85 satuan.

Faktor produksi $\mathrm{X}_{1}$ dan $\mathrm{X}_{2}$ dari hasil analisis secara ekonomis belum efisien sedangkan faktor produksi $\mathrm{X}_{3}$ dan $\mathrm{X}_{4}$ tidak efisien. Sementara hasil penelitian Fitriani dan Zaini (2012) menunjukkan tingkat efisiensi produksi secara ekonomis (efisiensi harga) usaha pembesaran ikan lele belum tercapai. Hal ini ditunjukkan dari rasio nilai produk marginal masing-masing faktor produksinya $\left(\mathrm{NPMX}_{\mathrm{i}}\right)$ dengan nilai masing- masing harga inputnya $\left(\mathrm{Px}_{\mathrm{i}}\right)$ tidak ada yang sama dengan satu.

Jadi pada usaha ini terjadi kelebihan pakan dan kekurangan benih untuk memakan pakan yang diberikan. Tenaga kerja dianggap berlebihan, hal ini dimungkinkan oleh kegiatan awal yaitu persiapan kolam yang membutuhkan tenaga kerja lebih banyak dan terlalu sering memberi makan juga persiapan kolam yang membutuhkan tenaga kerja yan banyak, sementara jumlah benih yang akan makan sedikit. Luas kolam juga perlu ditambah agar efisien tetapi kebutuhan luas kolam lebih sedikit dibandingkan dengan kebutuhan jumlah benih. Jadi hal pertama yang harus dipenuhi adalah penambahan jumlah benih. Hal ini terjadi juga berhubungan dengan identitas responden yang memiliki tanggungan keluarga, tingkat pendidikan, pengalaman usaha yang mempengaruhi dalam mengambil keputusan untuk memenuhi kebutuhan benih atau kebutuhan keluarga serta kecepatan memahami kondisi usahanya. Jadi kemungkinan ada masalah dalam menentukan skala prioritas.

Hal lain yang tidak dihitung dalam penelitian ini adalah dari hasil produksi benih yang berukuran lebih kecil dari ukuran 3-5 $\mathrm{cm}$ per ekor dan 5-7 $\mathrm{cm}$ per ekor dikembalikan ke kolam pendederan untuk dipelihara hingga ukuran benih yang diinginkan.

Kenyataan di lapangan memang menunjukkan bahwa semakin banyak benih diberi makan semakin cepat ukurannya bertambah. Tidak terlalu khawatir pada sisa pakan yang mengendap karena ikan lele mempunyai karakteristik mengejar makanan, makan terus apalagi pada waktu malam hari sehingga pada malam hari pakan diberikan lebih banyak. Ikan lele memiliki karakteristik kanibal terutama jika ikan dalam kondisi lapar. Ikan akan memakan sesamanya yang berukuran lebih kecil (Mahyudin 2008).

Tenaga kerja untuk kegiatan usaha ini termasuk tidak efisien dan harus dikurangi. Hal ini mungkin karena saat selesai melakukan kegiatan para tenaga kerja setelah selesai melakukan kegiatan terus menikmati kehidupan ikan lele di kolamnya jadi terkesan membuang waktu. Jadi berupa keuntungan sosial yang tidak bisa dihitung dengan angka.

Kondisi optimal adalah kondisi dimana penggunaan faktor-faktor produksi pada usaha pendederan ikan lele Sangkuriang mencapai tingkat efisiensi ekonomis, dimana 
petani dapat memperoleh keuntungan yang maksimum.

Tabel 3 menunjukkan bahwa penggunaan faktor produksi kolam $\left(\mathrm{X}_{1}\right)$ aktual (5.61) dan optimal (8.19) belum efisien $(1.46>1)$, masih perlu penambahan faktor produksi kolam sebesar 2.58 atau seluas $13.197 \mathrm{~m}^{2}$. Penggunaan faktor produksi benih $\left(\mathrm{X}_{2}\right)$ belum efisien $(2.39>1)$ dengan nilai aktual 4.52 sedangkan optimal 10.69, jadi perlu penambahan faktor produksi benih sebesar selisihnya yaitu 6.16 atau sebanyak 474.376 ekor. Penggunaan faktor produksi pakan $\left(\mathrm{X}_{3}\right)$ tidak efisien (0.20) dengan nilai aktual 5.25 dan optimal 0.955. Jadi mengurangi faktor produksi pakan sebesar 4.29 satuan atau sebanyak $73.552 \mathrm{~kg}$ adalah keputusan yang baik. Penggunaan faktor produksi tenaga kerja (X4) juga tidak efisien (-0.17) dengan nilai aktual 4.15 sedangkan nilai optimal -0.70. Di sini terjadi pemborosan tenaga kerja senilai 4.85 atau sebanyak 128.509 jam kerja sehingga perlu dikurangi sebanyak 128.509 jam kerja. Walaupun padat tebar 100 ekor $/ \mathrm{m}^{2}$ memberikan kelangsungan hidup $(94.3 \%)$, pertumbuhan mutlak (3.34 ton) dan laju pertumbuhan lele dumbo tertinggi (7.15\%) (Hermawan et al. 2012) dan jika diberikan probiotik $6 \mathrm{ml} / \mathrm{kg}$ dapat meningkatkan laju pertumbuhan harian sebesar $3.14 \%$ dan efisiensi pemberian pakan sebesar 43.39\% (Ahmadi et al. 2012) sedangkan menurut Shafrudin et al. (2006), benih ikan mengalami peningkatan ukuran berat (1.35 gram) dan panjang (5.1 $\mathrm{cm})$ Peningkatan kepadatan diikuti dengan penurunan pertumbuhan panjang $(p<0.05)$, kelangsungan hidup dan efisiensi pakan.

Tabel 1. Hasil uji parsial dan koefisien regresi faktor produksi pada usaha teknik pendederani ikan lele sangkuriang

\begin{tabular}{|c|c|c|c|c|c|}
\hline No & Variabel & Koef. Regresi & Std. Error & $\mathbf{t}_{\text {hitung }}$ & $t \alpha$ \\
\hline 1. & Konstanta & 0.58 & 0.84 & 0.69 & 2.08 \\
\hline 2. & Luas kolam (X1) & 0.26 & 0.12 & 2.07 & \\
\hline 3. & Benih (X2) & 0.39 & 0.18 & $2.17^{*}$ & \\
\hline 4. & Pakan (X3) & 0.10 & 0.04 & $2.35^{*}$ & \\
\hline 5. & Tenaga Kerja (X4) & -0.05 & 0.13 & 0.33 & \\
\hline
\end{tabular}

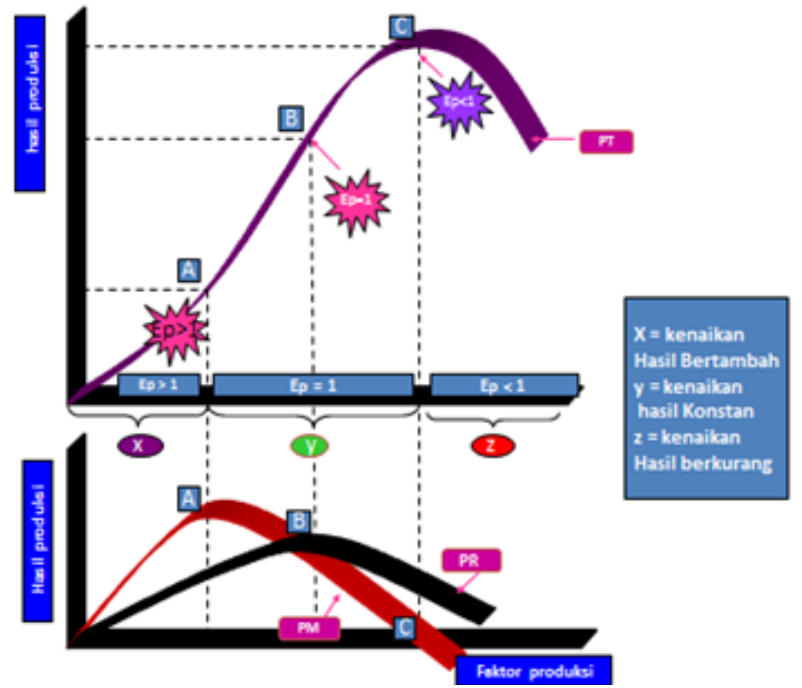

Gambar 1. Grafik fungsi produksi 
Tabel 2. Nilai NPM dan rasio NPM dan Px pada usaha pendederan ikan lele sangkuriang di Desa Sukaratu Kecamatan Sukaratu tahun 2013

\begin{tabular}{llcccccccr}
\hline No & Peubah & $\begin{array}{c}\text { Rata- } \\
\text { rata } \\
\text { peubah }\end{array}$ & $\begin{array}{c}\text { Rata- } \\
\text { rata } \\
\text { benih }\end{array}$ & Ep & $\begin{array}{c}\text { Prod } \\
\text { marj. }\end{array}$ & $\begin{array}{c}\text { Harga } \\
\text { Benih }\end{array}$ & NPM & BKM & Efisiensi \\
\hline & & X & PR & B & PM & Py & PM.Py & Px & NPM/Px \\
\hline 1. & L Kolam & 5.61 & 4.21 & 0.26 & 0.20 & 4.99 & 1.01 & 0.69 & 1.46 \\
2. & Benih & 4.52 & 4.21 & 0.39 & 0.36 & 4.99 & 1.84 & 0.78 & 2.36 \\
3. & Pakan & 5.25 & 4.21 & 0.10 & 0.08 & 4.99 & 0.42 & 2.29 & 0.18 \\
4. & TK & 4.15 & 4.21 & -0.05 & -0.05 & 4.99 & -0.27 & 1.61 & -0.17 \\
\hline
\end{tabular}

Tabel 3. Pendugaan kondisi faktor-faktor produksi optimal

\begin{tabular}{|c|c|c|c|c|c|c|c|c|}
\hline No & Peubah & Aktual & PR & B & Py & $\mathrm{Px}$ & Optimal & Selisih \\
\hline 1. & L Kolam & 5.61 & 4.21 & 0.26 & 0.20 & 4.99 & 8.19 & -2.58 \\
\hline 2. & Benih & 4.53 & 4.21 & 0.39 & 0.36 & 4.99 & 10.69 & -6.16 \\
\hline 3. & Pakan & 5.25 & 4.21 & 0.10 & 0.08 & 4.99 & 0.95 & 4.29 \\
\hline 4. & JOK & 4.15 & 4.21 & -0.05 & -0.05 & 4.99 & -0.70 & 4.85 \\
\hline
\end{tabular}

\section{KESIMPULAN DAN SARAN}

\section{Kesimpulan}

Penggunaan faktor produksi luas kolam, benih, pakan dan tenaga kerja secara simultan sangat mempengaruhi produksi usaha teknik pendederan ikan lele Sangkuriang. Secara parsial, faktor produksi benih dan pakan berpengaruh nyata terhadap produksi usaha pendederan ikan lele Sangkuriang. Sedangkan faktor produksi kolam dan tenaga kerja secara parsial tidak mempengaruhi produksi pada usaha teknik pendederan ikan lele Sangkuriang. Efisiensi penggunaan faktor-faktor produksi dalam usaha teknik pendederan ikan lele Sangkuriang faktor produksi luas kolam belum efisien dengan rasio NPM dengan nilai 1.46. Perlu penambahan luas lahan untuk kapasitas produksi saat ini senilai 2.58 satuan. Faktor produksi benih memiliki rasio NPMxi/Pxi sebesar 2.36 berarti lebih dari satu, hal ini menunjukkan bahwa faktor produksi benih belum efisien, perlu ditambah senilai 6.28 satuan agar optimal dan efisien. Faktor produksi pakan dan tenaga kerja penggunaannya tidak efisien sehingga perlu dikurangi sebesar selisih dari nilai aktual dan optimum. Berturut-turut perlu pengurangan senilai 4.29 dan 4.85 satuan.

\section{Saran}

Optimalisasi penggunaan faktor-faktor produksi perlu diperhatikan untuk mencapai hasil produksi yang optimal. Faktor produksi pakan sebaiknya dikurangi, tenaga kerja juga harus dikurangi karena cenderung pemborosan dan tidak menguntungkan baik secara teknis maupun ekonomis, sedangkan benih ditambah sehingga secara parsial maupun secara simultan berpengaruh nyata terhadap hasil benih ikan lele Sangkuriang. Perlu dilakukan pengurangan dan penambahan pada faktorfaktor produksi sesuai hasil analisis efisiensi dalam penggunaan faktor-faktor produksi pada usaha teknik pendederan ikan lele sangkuriang agar diperoleh hasil usaha yang efisien menguntungkan secara optimal. Terutama efisiensi dalam faktor produksi tenaga kerja dan pakan perlu dikurangi tetapi faktor produksi luas kolam dan benih perlu ditambah agar lebih menguntungkan.

\section{DAFTAR PUSTAKA}

Ahmadi H, Iskandar, Kurniawati N. 2012. Pemberian probiotik dalam pakan terhadap pertumbuhan lele Sangkuriang (Clarias gariepenus Burch) pada Pendederan II. Jurnal Perikanan dan Kelautan Vol. 3 No. 4 Desember 2012: 99-107. ISSN 20883137.

Az-zarnuji, Hendarto M. 2009. Analisis efisiensi budidaya ikan lele di 
Kabupaten Boyolali (Studi Kasus di Kecamatan Sawit Kabupaten Boyolali). eprints.undip.ac.id/29177/1/Jurnal. pdf

Fitrian, Zaini M. 2012. Efisiensi ekonomi usaha pembesaran Ikan Lele. Jurnal Ilmiah ESAI Volume 6, No 2, April 2012. ISSN No. 1978-6034

Gudjarati, Demodar N, Porter. 2009. DasarDasar ekonometrika. Salemba Empat Jakarta.

Hermawan AT, Iskandar, Subhan U. 2012. Pengaruh padat tebar terhadap kelangsungan hidup Lele Dumbo (Clarias gariepenus Burch) di Kolam

Kali Mener Indramayu. Jurnal Perikanan dan Kelautan Vol. 3. No. 3 September 2012: 85-93. ISSN 20883137.

Khairuman A, Khairul. 2008. Buku pintar budidaya 15 ikan konsumsi. Agromedia
Pustaka. Jakarta.

Mahyudin K. 2008. Panduan lengkap agribisnis Lele. Penebar Swadaya. Depok.

Shafrudin D, Yuniarti, Setiawati M. 2006. Pengaruh kepadatan benih ikan Lele Dumbo (Clarias sp.) terhadap produksi pada system budidaya dengan pengendalian nitrogen melalui penambahan tepung terigu. Jurnal Aquakulutur Indonesia, 5(2) 137 - 147.

Soekartawi. 2002. Agribisnis. teori dan aplikasinya. PT Raja Grafindo Persada. Jakarta.

Soekartawi. 2002. Prinsip dasar ekonomi pertanian. teori dan aplikasinya. PT Raja Grafindo Persada. Jakarta.

Sumarjono D. 2004. Ekonomi produksi. Universitas Dipenogoro. Semarang. 